\title{
Operations Research, Economic Development, and Social Mobility
}

\author{
Aniekan A. Ebiefung ${ }^{1} \&$ Michael M. Kostreva ${ }^{2}$ \\ ${ }^{1}$ Department of Mathematics, The University of Tennessee at Chattanooga, Chattanooga, USA \\ ${ }^{2}$ Department of Mathematical Sciences, Clemson University, Clemson, USA \\ Correspondence: Aniekan Ebiefung Department of Mathematics, The University of Tennessee at Chattanooga, \\ Chattanooga, TN 37403, USA.
}

Received: January 24, 2018 Accepted: February 19, 2018 Online Published: March 9, 2018

doi:10.5539/jmr.v10n3p1

URL: https://doi.org/10.5539/jmr.v10n3p1

\begin{abstract}
It is the primary responsibility of governments to embark on economic development programs. Recently, however, communities, non-governmental organizations, individuals, and private sectors are carrying out activities that lead to growth, economic productivity, and development. The objective of this paper is to examine some of the ways in which these entities use Operations Research (OR) tools in their efforts to facilitate the development of their societies and in the process alleviate poverty and foster social mobility.
\end{abstract}

Keywords: Operations Research, economic development, social mobility, poverty, linear programming

\section{Introduction}

\subsection{Origin of Operations Research}

The need for societies to come up with programs that bring economic development to their people was recently brought to the lime light. First, by the speeches of Pope Francis (John Nichols, 2013) and President Obama (Amy Davidson, 2013) on poverty. Second, the celebration of the $50^{\text {th }}$ anniversary of the "War on Poverty" declared by President Lyndon B. Johnson in 1964. In this paper, we examine some of the uses of OR techniques in efforts to alleviate poverty in many parts of the world.

From time immemorial, mankind has been looking for the best way to solve problems. These include finding the best way to hunt, the most safe and shortest path to get to the river to fetch water, to move goods to market, and to avoid predators. All of these were done in an ad-hoc and haphazard basis before the twentieth century.

One of the first known attempts to use mathematics to find an optimal solution to a problem are recorded in Bolza (1904) and Valentine (1937), where they discussed finding the optimality conditions for systems of linear equations in the context of Calculus of Variation. This was followed by Karush (1939) who, as a part of his master's thesis, gave conditions for finding extreme values of functions with inequality side constraints. However, the work that could be considered the harbinger of the current field of OR methodology was the work of the Soviet mathematician Kantorovich (1939). While working for the Soviet government, he was instructed to help optimize production at a plywood factory. Kantorovich solved the problem for the government by formulating linear programming production and distribution models. Unfortunately, nobody in the Soviet Union or the West paid serious attention to Kantorovich work at the time.

The elevation of OR into a field of study, as we know it today, started during the Second World War when British and American military planners decided to use scientific methods to plan military operations, such as moving troops, ammunition, and supplies or how to best deploy radar systems. In fact, the phrase "operations research" can be literally interpreted to mean exploring how to efficiently manage, run or organize the operations or activities of an organization. Thus OR consists of tools that management can use to make decisions on how to run the operations of an organization subject to limited resources.

The word "operations" is military oriented. It is not surprising that when OR tools were used in different disciplines, different names were adopted. For example, in business schools, the phrase "Management Sciences" or "Decision Sciences" is used for operations research, while "Mathematical Programming" is the favorite equivalent to those in more quantitative disciplines. It is noteworthy that in January 1995, the Operations Research Society of America and The Institute of Management Sciences joined together to become the Institute for Operations Research and Management Sciences (INFORMS). 


\subsection{What is Economic Development?}

Economic development has something to do with activities and policies undertaken by government, communities, individuals, private sectors, and businesses in order to provide society with its material needs (O'Sullivan et al, 2003). These include food, affordable housing, quality education, safety, health, transportation, and technology. We are interested in how stakeholders use OR tools in their efforts to make life better for their people. The International Federation of Operational Research Societies (2012) has identified finance, marketing, production, project management and control, logistics and supply chain, personnel and manpower planning, policy and strategic planning, information technology, and service operations as some of the areas in which OR tools can be used to enhance development. We shall only examine few areas in this paper.

\subsection{What is Social Mobility?}

In all societies, citizens are pigeon-holed into social classes. For example, we hear about the lower class, the middle class, and the upper class. In some of these classes, you could have divisions such as middle lower class or top upper class. In some countries, the top $1 \%$ of the upper class own most of the wealth. For example, the top $1 \%$ of the upper class in the US own about $20 \%$ of the nation's wealth (Financial Samurai, 2011). In some countries in Africa or the Middle East, the percentage may be higher!

According to Dictionary.Com (2016), social mobility is the "the ability of individuals or groups to move upward or downward in status based on wealth, occupation, education, or some other social variable." Obviously, everybody would like to move to a higher social class. What are the hurdles that one needs to jump over in order to move to a higher social class? The bets are in quality education, good employment opportunities, networking, marriage or luck! We are interested in how the use of OR tools assist in moving individuals into higher social classes.

\section{How OR Tools Affect Economic Development and Social Mobility}

\subsection{OR as a Business Decision Support Tool}

The most important responsibility of a leader: president, chairman, chief executive officer, et cetera, is decision making. As our societies become more complex, situations that require decision making are also becoming more complicated. In the past, for example, it was sufficient for a firm to only produce quality goods. But now it has to produce quality goods more cheaply than the competitor, manage procurement and inventory, keep up with more government regulations, predict future needs, distribute goods and services more efficiently, et cetera. Because the task of decision making is becoming more complex and risky, policy makers are looking for scientific tools that could aid the decision making process. OR is one of the tools that management uses to enhance the quality of the decision making process.

Business leaders and policy makers are using OR techniques to assist them in decision making in ways that directly or indirectly lead to poverty alleviation and economic development. For example, OR tools are used in optimal facility location, product design and manufacturing, inventory control, capital investment, and manpower planning (Winston, 2004).

When a CEO of a company makes a right decision, the effect could be increased productivity, increased profit, pay increases for workers, provision of bonuses to workers or gaining new market share that might require new hiring. In some companies, bonuses could be more than ten times the regular pay. Employees wait for these bonuses for major purchases such as cars, housing, clothing, pay school fees for children or relatives, marry, and the list goes on. These resulting activities and their multiplier effects help move some of the beneficiaries to a higher social class.

\subsection{OR in Project Planning and Scheduling}

It takes time, energy, and resources to plan and execute any worthwhile development project. In some instances, it could take months or years to complete them. These projects consist of different activities, some of which must be completed before others begin. To ensure timely completion of projects, OR tools are often used to determine the earliest and latest completion times for each activity, and by how much the duration of an activity can be increased without delaying the project. Timely completion of projects is important, since projects not completed on time shortchange the objectives of the development projects or lead to additional cost. These costs could be monetary or citizens suffering. When a project needs to be completed ahead of schedule, OR tools, such as linear programming, can be used to estimate the additional resources needed to meet the new deadline (Winston, 2004).

Two specific OR project planning and scheduling techniques are the Critical Path Method (CPM) and the Program Review and Evaluation Technique (PERT). The CPM was developed by Morgan Walker at DuPont, while James Kelley, Jr., invented the PERT at Remington Rand (Kelly and Walker, 1959). Figure 1.1 shows the CPM and PERT process. 


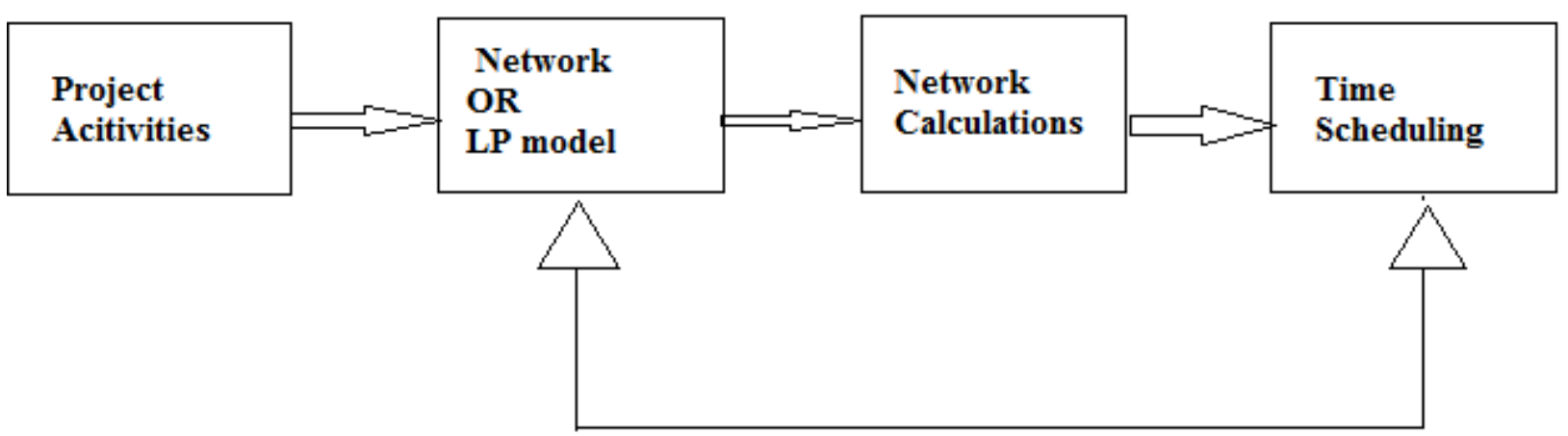

Successful completion of these projects contributes to job creation, community empowerment, most importantly, meeting the economic goals that led to the implementation of the projects in the first place. According to Harry (1996), CPM, and PERT contributed immensely to the timely completion of the World War II Manhattan Project.

\subsection{OR in Project Analysis and Evaluation}

In an era of scarce resources, policy makers demand accountability. They want to make sure that scarce resources are not wasted, projects are efficiently completed on time, and projects' goals are achieved. They are also interested in how lessons learned from one project can be used to improve the implementation of other projects in the future.

OR is one of the tools that can be used to achieve these goals. For example, a linear or nonlinear programming could be used to construct and analyze different implementation scenarios or policy alternatives. Depending on the nature of the model, sensitivity analysis could be performed to see how changes in problem inputs affect the solution. This analysis could assist in a comparison of expected outcomes to actual outcomes, and hence determine the effectiveness of the project in meeting expected development goals.

China is one of the developing countries that embraces the use of OR tools not only in business, but also in government and non-governmental organizations. In the 1980s, China developed a massive information system called the State Economic Information System (SEIS), which consists of many independent information sub-systems (Zhang, 1999). Because the SEIS is distributed to many regions and cities in China, it became necessary to evaluate its effectiveness in achieving its goals. The responsibility for evaluating and managing the SEIS fell on the shoulders of the State Information Center (SIC). In order to coordinate the activities of the different information sub-systems and evaluate their contribution to economic development, SIC constructed an extensive OR model. The model consists of parametric programming, analytic hierarchy process, and data envelopment analysis. According to the authors, the new model can also be used as a decision management tool in other areas such as economics and finance. The OR model won IFORS's first prize in OR in Development in 1996. According to the authors, the OR model helped the SEIS to determine the roles that the independent information systems played "in the local social and economic development" of China.

\subsection{Using OR Models to Predict Future Needs}

To ensure future economic viability and competitiveness, many societies proactively anticipate their future economic needs. For example, these societies may want to estimate their educational needs as the population grows, health needs as the population ages, or energy needs of tomorrow. As the population grows due to birth rate increase, it is important for society to project the number of new teachers and schools it will need in order to train its future workforce. When the population ages, a society will need more nurses, doctors, or more medical facilities. As future needs increase in different area of human activities, so will future energy and food needs. In this section, we examine some of the ways that some societies or nations use OR to predict their energy and food needs.

\subsubsection{Predicting Energy Needs}

An example of the use of OR model to project future energy needs is the U. S. Energy Information Administration's Intermediate Forecasting System. According to Murphy (1998), "the system contains representations of supply and demand for all of the major fuels consumed in the United States, and is a partial equilibrium model containing a large number of equations and inequalities."

India, the world's second most populous country with 1.27 billion people, is rapidly becoming highly industrialized. Consequently, energy supply is not keeping up with demand. The national electricity grid system consists of Regional Electricity Boards that are almost independent of the State Electricity Board (ESB).

Power outages are common and power sharing among the regions is not optimized as "there are no guidelines to determine the exchange prices for inter-regional power transfer," Chaturvedi and Bhattachrya (1999). To solve problems 
associated with power distribution and capacity slack, the authors constructed a mixed integer programming model called NATGRID-TR. The model can be used by the SEB to coordinate the operations of the different regional grids and estimate future transmission links as the population increases.

The power sectors in most developing countries, for example India and Nigeria, do not have the capacity to meet household or industrial demands. In this situation, businesses cannot succeed and consequently, these countries have high unemployment rates. If a region's or country's electricity supply becomes inadequate due to population increase or lack of expansion, then it is quite possible for existing businesses to relocate to regions or countries with adequate electricity supply. The resulting effect of such action will be more unemployment. Thus using OR tools to effectively predict future energy needs is important for economic development and stands to enhance the ability of people to move from one social class to another.

\subsubsection{Predicting Future Food Needs}

The ability of a country to feed its citizens is important for economic, health, and national security reasons. It is therefore not surprising that the world's most populous country, China with about 1.35 billion people, takes accurate prediction of grain output seriously. In Chen et al (2001), an OR model used by the Chinese government to predict grain output is described. The model consists of input-occupancy-output-analysis and a nonlinear forecasting model that incorporate a law of diminishing returns. This model, according to the authors, provides a more accurate prediction of grain output than the Meteoric and Remote Sensing techniques employed by the U.S. and other countries.

\subsection{OR in Efficient Distribution of Services}

Many economic development projects involve the provision of amenities and services such as water and electricity to the people in need. Unfortunately, the goals of such projects may be stymied by lack of efficient and fair distribution systems. Different providers are using disparate OR tools to address their distribution problems. In this paper, we examined few cases that involve water and electricity distribution.

\subsubsection{Efficient Distribution of Water}

Udias et al (2012) described a cost-efficient equitable OR tool that they used to distribute water in the Kabylia region of Algeria. The model uses a bi-criteria optimization technique. In Raad et al (2009), a multi-objective optimization model and meta-metaheuristics are used in the efficient design of an urban water distribution system in South Africa.

Water is not only essential for life, it is also essential for the production of food, manufacture of goods, and construction of roads and facilities. Availability of water contributes to economic and social development. Therefore, applying OR tools for efficient distribution of water helps people move up the social ladder.

\subsubsection{OR in Efficient Distribution of Electricity}

OR tools are also used in the distribution of electricity. In Chinwuko et al (2012), an optimization model for electricity distribution planning for Awka, a region in Eastern Nigeria, is provided. The model uses dynamic programming to optimize power outages cost, feeder cost, substation cost, and energy losses. To optimize the distribution planning, non-linear mixed integer programs were used. The authors report that the model was applied to power distribution planning in Awka in Eastern Nigeria.

In Duta et al (1994), the optimal allocation of electricity in a steel plant in India, among essential loads and nonessential loads, is modeled as a linear programming problem. The authors estimate that the model has "increased the net profit per ton of saleable steel by 58\%," and so far has a cumulative monetary benefit of at least 73 million US dollars.

\subsection{OR as a Decision Support tool in School Management}

Education is one of the skills needed for national development, poverty alleviation, and social mobility. In this section, we focus on how OR tools are used for efficient school management in different developing countries.

The Jesuit order, Fe y Alegria (FyA), runs hundreds of schools in Bolivia, one of the poorest countries in Latin America. To efficiently manage these schools and share cases of best practices among schools in the system, FyA called on the assistance of OR tools. In Figueiredo and Barrientos (2011), a data envelopment analysis (DEA) based decision support technique that FyA uses is provided. According to the authors, the implementation of the DEA-decision support system had tangible benefits. These include the discovery that FyA schools are more efficient in their use of limited resources, the identification of high efficiency practices, the sharing of good practices with other schools in the system, and the use of the favorable findings in fund raising activities.

The second case of the use of OR tool in school management of interest is recorded in Epstein et al (2002). Chile, a country in South America, provides school meals to about 1.3 million low income students at a cost of over US\$180 million, according to the authors. Food suppliers are selected by a bidding process. "To improve the quality of the 
assignment in the auction process," the authors constructed a mixed integer programming model which the state uses to improve the biding process. The authors claim that the implementation of the model led to transparency, objectivity, flexibility, and efficient allocation of food suppliers or concession holders. Financially, "the new methodology improved the price-quality ratio of the meals with yearly savings of about US\$40 million-equivalent to the cost of feeding 300,000 children during one year," according to the authors.

The third case we want to report is the use of the p-median method to optimize the location of high schools in Dakar, Senegal. The Education Department Inspection (EDI) in Dakar has the responsibility of placing pupils in high schools after they have successfully passed an entranced examination (Ndiaye, 2012). As the number of students increases, it became necessary to establish more high schools. The authors use the p-median technique to determine the best location of the high schools. The implementation ensured that the "distances" between schools and students' homes satisfy "the distance -standards imposed by international organizations." The model was successfully used to solve the EDI's high school allocation problem in the city of Dakar, Senegal.

In this section, we have seen how OR tools are used to provide quality and accessible education to children, especially those from low income families. For children in these circumstances, education is the only means and hope by which they can improve their living standard, move up the social ladder, and advance their social standing in the society.

\section{Conclusion}

In this paper, we consider some of the ways in which governments and non-governmental organizations (NGOs) have used OR tools for project planning and scheduling, project analysis and evaluation, prediction of food and energy needs, efficient distribution of water and electricity, and efficient management of schools. In each case, we discussed how each activity contributed to economic development and social mobility. It is our hope that knowledge of how OR can be used for economic development and poverty alleviation will encourage readers, especially those from poor countries, to think creatively of how they could use OR tools to assist their governments and NGOs in development projects in their communities.

\section{References}

Baker, S. (2004). The Critical Path Method. http://hspm.sph.sc.edu/Courses/J716/CPM/CPM.html (Accessed:September $24,2013)$.

Bolza, O. (1904). Lectures on the Calculus of Variations. University of Chicago Press, Chicago.

Chen, X., Pan, X., \& Yang, C. (2001). On the study of China's grain prediction. International Transactions in operational research. 8, 429-437. https://doi.org/10.1111/1475-3995.00275

Chinwuko, C. E., Chukwuneke, J. L., Okolie, P. C., \& Dara, E. J. (2012). Modeling and optimization of electricity distribution planning systems using dynamic programming techniques: A case of Power Holding Company of Nigeria. International Journal of Multi-Disciplinary Sciences and Engineering, 3, 39-46.

Davidson A. (2013). Economic Inequality: A Matter of Trust? The New Yorker, New York, United States of America. http://www.newyorker.com/news/amy-davidson/economic-inequality-a-matter-of-trust (Accessed: December 4, 2013)

De Figueiredo, J. N., \& Barrientos, M. A. M. (2011). A decision support methodology for increasing school efficiency in Bolivia's low-income communities. International Transactions in Operational Research 19, 99-121. https://doi.org/10.1111/j.1475-3995.2011.00821.x

Dutta, D., Sinha, G., Roy, P. N., \& Mitter, N. (1994). A linear programming model for distribution of electrical energy in a steel plant. International Transactions in Operational Research 1, $11-29$. https://doi.org/10.1016/0969-6016 (94) 90042-6

Epstein, R., Henriqueg, L., Catalan, J., Weintraub, G., Martinez, C., \& Espejo, F. (2004). A combinatorial auction improves school meals in Chile: a case of OR in developing countries. International Transactions in Operational Research, 11, 593-612. https://doi.org/10.1111/j.1475-3995.2004.00480.x

James, K., \& Morgan, W. (1959). Critical-Path Planning and Scheduling. Proceedings of the Eastern Joint Computer Conference.

Kantorovich, L. V. (1939). Mathematical Methods of Organizing and Planning Production. Management Science, 6(July, 1960), 366-422.

Karush, W. (1939). "Minima of Functions of Several Variables with Inequalities as Side Constraints". M.Sc. Dissertation. Dept. of Mathematics, Univ. of Chicago, Chicago, Illinois.

Ndiaye, F., Ndiaye, B. M., \& Ly, I. (2012). Application of the p-median problem in school allocation. American Journal of 
Operations Research, 2, 253-259. https://doi.org/10.4236/ajor.2012.22030

Nichols, J. (2013). Pope: “King Money” Culture is Hurting Young and Old. The Nation. http://billmoyers.com/2013/12/02/the-pope-versus-unfettered-capitalism/ (accessed December 2, 2013)

O'Sullivan, A., \& Sheffrin, S. M. (2003). Economics: Principles in action. Pearson Prentice Hall, Upper Saddle River, New Jersey, United States.

Samurai, F. (2011). How Much Money Do The Top Income Earners Make? Financial Samurai. http:www.financialsamurai.com/2011/04/12/how-much-money-do-the-top-income-earners-make-percent/

Raad, D., Sinske, A., \& van Vuuren, J. (2009). Robust multi-objective optimization for water distribution system design using meta-metaheuristic. International Transactions in operational Research, 16, 595-626. https://doi.org/10.1111/j.1475-3995.2009.00705.x

Social Mobility, Dictionary.com. Dictionary.com's 21st Century Lexicon. Dictionary.com, LLC. http://www.dictionary.com/browse/social-mobility (Accessed: March 15, 2016).

Thayer, H. (1996). Management of the Hanford Engineer Works in World War II: How the Corps, DuPont and the Metallurgical Laboratory fast tracked the original plutonium works. ASCE Press, 66-67. https://doi.org/10.1061/9780784401606

Udias, A., Insua, D. R., Cano, J., \& Fellag, H. (2012). Cost Efficient equitable water distribution system in Algeria: a bicriteria fair division problem with network constraints. International Transactions in operational Research, 19, 675 - 693. https://doi.org/10.1111/j.1475-3995.2012.00846.x

Valentine, F. A. (1937). The problem of Lagrange with differential inequalities as added side conditions. In: Contributions to the Calculus of Variations. University of Chicago Press, Chicago, 403-447.

Zhang, X., \& Cui, J. (1999). A project evaluation system in the state information system of China: An operations research practice in public sector. International Transactions in Operational Research, 6, 441-452. https://doi.org/10.1111/j.1475-3995.1999.tb00166.x

\section{Copyrights}

Copyright for this article is retained by the author(s), with first publication rights granted to the journal.

This is an open-access article distributed under the terms and conditions of the Creative Commons Attribution license (http://creativecommons.org/licenses/by/4.0/). 